\title{
Research on Students' Error Pattern in Solving First Order Differential Equations
}

\author{
Nur Azila Yahya, Junaida Md Said, Samsiah Abdul Razak, Nurul Husna Jamian, Elizabeth Arul
}

\begin{abstract}
First order differential equations can be classified as separable, linear, exact, homogeneous and Bernoulli. Each type has a very systematic method of solution. An analytic method of solution is offered the student for each class of equation whereas integration is essential in the solution process. Hence integration, formulas and steps are important in these kinds of approaches. This study aims to investigate students' error pattern in solving first order differential equations and focused only to separable, homogeneous and Bernoulli. A test consisting of the three different first-order differential equations was prepared for students. 41 students were asked to solve the equations on the test using appropriate methods. The 41 scripts were examined with a focus on the integration techniques used and the final answers given by students. The results were analyzed using IBM SPSS Statistics 23 and the items such as frequency, mean and standard deviation are used to assess students' understanding and their ability to solve first order differential equations.
\end{abstract}

Keywords: Bernoulli, homogeneous, integration techniques, ordinary differential equations, separable.

\section{INTRODUCTION}

The study of Calculus is a crucial prerequisite in disciplines such as Physics, Engineering, Economics and Medicine. Differentiation and integration techniques are among the most important topics in Calculus where mastery in these topics greatly helps students in mathematical subjects such as Statistics, Analytical Geometry and Algebra. In many universities, Ordinary Differential Equations (ODE) is studied in mathematics before they are applied in other disciplines. Ordinary Differential Equations (MAT300) is one of the compulsory courses enrolled by the full-time students in the Diploma in Mathematical Sciences (CS143) program at Universiti Teknologi MARA (UiTM). In order to enroll for ODE in UiTM, students must have passed two pre-requisite courses namely Calculus and Linear Algebra [1], [2].

In the ODE course, there are several types of first-order differential equations such as separable, linear, exact, homogenous, and Bernoulli equations. Solving these

Revised Version Manuscript Received on September 16, 2019. Universiti Teknologi MARA, Perak Branch, Tapah Campus, Perak, Malaysia.

Junaida Md Said, Faculty of Computer and Mathematical Sciences, Universiti Teknologi MARA, Perak Branch, Tapah Campus, Perak, Malaysia.

Samsiah Abdul Razak, Faculty of Computer and Mathematical Sciences, Universiti Teknologi MARA, Perak Branch, Tapah Campus, Perak, Malaysia.

Nurul Husna Jamian, Faculty of Computer and Mathematical Sciences, Universiti Teknologi MARA, Perak Branch, Tapah Campus, Perak, Malaysia.

Elizabeth Arul, Faculty of Computer and Mathematical Sciences, Universiti Teknologi MARA, Perak Branch, Tapah Campus, Perak, Malaysia
Nur Azila Yahya, Faculty of Computer and Mathematical Sciences,

equations requires knowledge of integration techniques. Hence, students need to recall these techniques that they were taught more than a semester earlier. Integration requires the use of formula and techniques which students have to master in order to solve first order differential equations. The inability of students to connect the concepts in differential and integral calculus to ODE concepts is a source of concern for students. Many students are therefore, not able to solve ODE problems accurately due to inability to work out the steps required in the solution procedure [3], [4].

Literature reveals that various researchers have done their best to recognize the troubles emerged during educating and learning differential equations course and they additionally attempted to beat these issues by utilizing various methodologies. A significant part of the exploration on the teaching and learning of differential equations centers around Literature reveals that various researchers have done their best to recognize the troubles emerged during educating and learning differential equations course and they additionally attempted to beat these issues by utilizing various methodologies. A significant part of the exploration on the teaching and learning of differential equations centers around the three themes: acquainting a geometric approach with comprehending differential equations; students' conception of the solution to a differential equation; and the effect of a change in pedagogy on conceptual understanding [5]. The obstacles faced by students with non-routine problems were caused by the weakness of students in understanding the basic concept of ODE and symbols [6].

One of the challenges facing students taking ODE is the solution process involved in the solving of ODEs as this involves differentiation and the application of integral calculus and various integration techniques. This often involves long and tedious calculations. Algebraic based solution is traditional and is based on several steps or procedure to solve the DEs analytically. This is the main difficulties that students faced in solving algebraic based solution due to incorrect choice of suitable method of solution or the wrong process of integration. Analytically is a solution to a differential equation is a function that satisfies the ordinary differential equation.

Before being able to solve integration problems, students are expected to have prior knowledge of differentiation and integration of the following functions: exponential functions, algebraic functions, trigonometric functions, hyperbolic functions, logarithmic functions, inverse hyperbolic 
functions and inverse trigonometric functions. Other problems require the application of the following techniques: Integration by parts to be used when we are integrating a product of two functions; algebraic substitution to be applied for algebraic terms (this is also called the u-substitution method); trigonometric substitution to be employed when the integrand contains expression of the radical form; partial fraction decomposition to be used to integrate rational functions; reciprocal substitution to be applied to integrate algebraic functions and half-angle substitution to be employed to integrate expressions in trigonometric form [7]-[9].

Most of the previous studies, focused on finding competent strategies in teaching and learning of ODE only. However, there is lack in-depth study on the solution method provided by students. Therefore, the authors were interested in investigating students' error pattern in solving first-order differential equations, particularly in integration that requires the use of formulas and techniques. This study also aims to investigate students' ability in identifying the suitable technique of integration required to solve a differential equation. In addition, this study will give fundamental input to the students and instructors recognize and comprehend the idea of troubles in learning and teaching first order differential equations.

\section{METHODOLOGY}

The population in this study was all diploma students $(\mathrm{N}=41)$ who enrolled for MAT300 course in UiTM Perak Branch, Tapah Campus during the March 2019 session. This course is taken by part 5 students. MAT 300 consists of five chapters which cover 16 sub-topics as shown in Table 1.

Table 1: Chapter and subtopics covered in MAT300

\begin{tabular}{|l|l|}
\hline $\begin{array}{l}\text { Chapte } \\
\mathbf{r}\end{array}$ & Subtopic \\
\hline 1 & $\begin{array}{l}\text { Terms such as order, degree, linearity, } \\
\text { dependent and independent variables. }\end{array}$ \\
\hline 2 & $\begin{array}{l}\text { Separable first order DEs, homogeneous first } \\
\text { order DEs, exact first order DEs, linear first } \\
\text { order DEs and Bernoulli equations. }\end{array}$ \\
\hline 3 & $\begin{array}{l}\text { Application of first order DEs - growth/decay } \\
\text { problems, Newton's Law of cooling, and } \\
\text { mixture problems. }\end{array}$ \\
\hline 4 & $\begin{array}{l}\text { The Wronskian and linear independence, } \\
\text { homogeneous second order DEs with constant } \\
\text { coefficients, reduction of order and finding } \\
\text { second solutions, non-homogeneous DEs using } \\
\text { the method of undetermined coefficients, and } \\
\text { non-homogeneous DEs using variation of } \\
\text { parameters. }\end{array}$ \\
\hline 5 & $\begin{array}{l}\text { Applications of second order DEs - } \\
\text { spring/mass systems and LRC circuits. }\end{array}$ \\
\hline
\end{tabular}

In this study we only focused on Chapter 2 which involves solving first-order differential equations. Every student who participated in the study was given a test on first order differential equations. Students had to solve a separable equation, a homogeneous differential equation, and a Bernoulli equation. Each question contributed 10 marks. The questions on the test are as follows: i. Find the general solution for the differential equation $x\left(1+x^{2}\right) e^{y} \frac{d y}{d x}-1=e^{2 y}$.

ii. Show that the following differential equation is homogeneous. Hence, solve $x\left(9 x^{2}+3 y^{2}\right) d x=(2 x y) d y$ using an appropriate substitution.

iii. Solve the Bernoulli differential equation: $\frac{d y}{d x}-\frac{y}{3 x}=e^{x} y^{4}$ using an appropriate substitution.

This common test was given during week 7 of the semester after all topics had been covered comprehensively in class. Students were given one hour to complete the test. Students also were given one week's notice to prepare for the test. This test was given to measure students' understanding in first order differential equations and their ability to apply integration techniques. The total marks obtained for each question was recorded and the data was analyzed using IBM SPSS Statistics 23. The conceptual framework in this study is presented in Fig. 1.

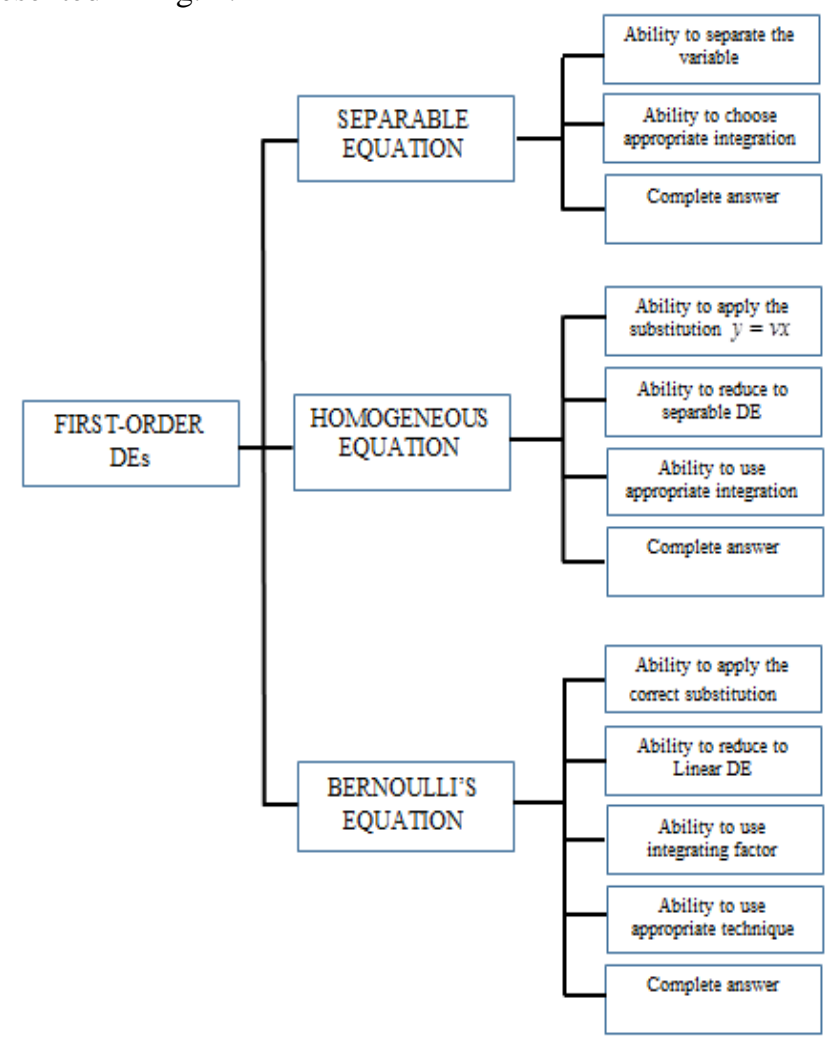

Fig. 1: Conceptual framework

Fig. 1 shows that the test consisted of 3 types of first-order differential equations. There are 3 steps in the solution process of separation equation: separate the variables choose appropriate integration technique and complete the answer. Solving the homogeneous equation requires the following steps: apply the correct substitution to reduce the DE to a separable equation, apply a suitable integration technique and complete the answer. Lastly, solving the Bernoulli equation requires the following steps: apply the correct substitution to 
reduce the DE to a linear DE, using the integrating factor method, apply a suitable integration technique and complete the answer.

\section{RESULTS AND DISCUSSION}

\section{Description of students' background}

Fig. 2 shows the demographic information of respondents. Out of 41 students, $90.20 \%$ of the population comprised of female respondents and the remaining $9.80 \%$ were males.

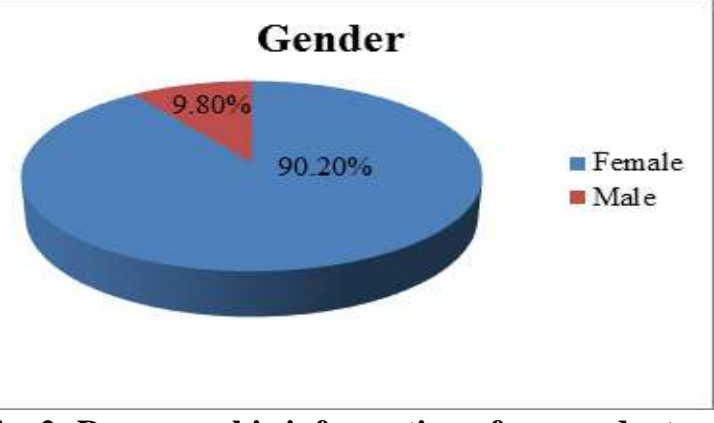

Fig. 2: Demographic information of respondents $(\mathrm{N}=\mathbf{4 1})$

Description of students' performance for every question

The following Table 2 analyzed the students' performance according to three categories: Complete answer (C), Incomplete answers (I) and Wrong answer (W).

Table 2: Descriptions of completion level

\begin{tabular}{|l|l|}
\hline $\begin{array}{l}\text { Complete } \\
\text { answer (C) }\end{array}$ & $\begin{array}{l}\text { Students get full marks where they } \\
\text { give a proper working calculation. }\end{array}$ \\
\hline $\begin{array}{l}\text { Wrong answer } \\
\text { (W) }\end{array}$ & $\begin{array}{l}\text { Students get zero marks where they } \\
\text { do not answer or the answer given is } \\
\text { absolutely incorrect. }\end{array}$ \\
\hline $\begin{array}{l}\text { Incomplete } \\
\text { answer (I) }\end{array}$ & $\begin{array}{l}\text { Other than category C and W, where } \\
\text { they answer the question and get } \\
\text { some marks for working. }\end{array}$ \\
\hline
\end{tabular}

Description of students' performance in Question 1

Table 3: Description of marks for separable DE

\begin{tabular}{|c|c|c|c|c|c|}
\hline & Case & $\begin{array}{c}\text { Mea } \\
\mathbf{n}\end{array}$ & SD & $\begin{array}{l}\text { Overal } \\
\text { I Mean }\end{array}$ & SD \\
\hline \multirow{4}{*}{ Q1 } & $\begin{array}{c}\text { Separable } \\
\text { (1 mark) }\end{array}$ & 0.671 & 0.442 & \multirow{4}{*}{2.805} & \multirow{4}{*}{3.557} \\
\hline & $\begin{array}{l}\text { u-substitution } \\
\text { (3 marks) }\end{array}$ & 0.634 & 1.096 & & \\
\hline & $\begin{array}{c}\text { Partial } \\
\text { Fraction } \\
\text { (4 marks) }\end{array}$ & 1.098 & 1.574 & & \\
\hline & $\begin{array}{c}\text { Last Answer } \\
\text { (2 marks) }\end{array}$ & 0.427 & 0.771 & & \\
\hline
\end{tabular}

Based on Table 3, the mean for separation of variables was 0.671. This implies moderate score out of one mark. Meanwhile, the mean for obtaining partial fractions was 1.098 and this implies a poor score out of 4 marks. The mean for $\mathrm{u}$-substitution and final answer were 0.634 and 0.427 respectively and these imply very poor score. On average, students scored 2.805 marks indicating students performed poorly in Question 1.

Table 4: Performance of students in Question 1

\begin{tabular}{|c|c|c|c|c|c|c|c|c|}
\hline \multirow[t]{2}{*}{$\begin{array}{c}\text { Com } \\
\text { pletion } \\
\text { Level }\end{array}$} & \multicolumn{2}{|c|}{$\begin{array}{c}\text { Separab } \\
\text { le } \\
(1 \mathrm{~m})\end{array}$} & \multicolumn{2}{|c|}{$\begin{array}{c}\text { u- } \\
\text { substituti } \\
\text { on } \\
(\mathbf{3} \mathbf{~ m}) \\
\end{array}$} & \multicolumn{2}{|c|}{$\begin{array}{r}\text { Partial } \\
\text { Fractions } \\
(4 \mathrm{~m})\end{array}$} & \multicolumn{2}{|c|}{$\begin{array}{r}\text { Last } \\
\text { Answer } \\
(2 \mathrm{~m})\end{array}$} \\
\hline & f & $(\%)$ & f & $\%$ & f & $(\%)$ & f & $(\%)$ \\
\hline C & 25 & 61 & 6 & 14.6 & 7 & 17.1 & 6 & 14.6 \\
\hline I & 5 & 12.2 & 7 & 17.1 & 11 & 26.8 & 6 & 14.7 \\
\hline W & 11 & 26.8 & 28 & 68.3 & 23 & 56.1 & 29 & 70.7 \\
\hline Total & 41 & 100 & 41 & 100 & 41 & 100 & 41 & 100 \\
\hline
\end{tabular}

Table 4 shows that generally, students $(\mathrm{f}=25,61 \%)$ were able to separate the variables, however most of them obtained wrong answer in integrating the function using $\mathrm{u}$-substitution $(\mathrm{f}=24,68035)$ and partial fractions $(\mathrm{f}=23,56.1 \%)$ respectively. Therefore, only 6 students were able to answer Question 1 correctly and 6 students gave incomplete answer. The other 29 students got the answer wrong.

Description of students' performance in Question 2

Table 5: Description of marks for homogeneous DE

\begin{tabular}{|c|c|c|c|c|c|}
\hline & Case & $\begin{array}{c}\text { Mea } \\
\mathbf{n}\end{array}$ & SD & $\begin{array}{c}\text { Overal } \\
\text { I Mean }\end{array}$ & SD \\
\hline \multirow{2}{*}{ Q2 } & $\begin{array}{c}\text { Apply } \\
\text { y = vx } \\
(6.5 \text { marks })\end{array}$ & 4.024 & 2.156 & & \\
\cline { 2 - 5 } & $\begin{array}{c}\text { u-substitution } \\
(1.5 \text { marks })\end{array}$ & 0.671 & 0.755 & 5.524 & 3.484 \\
\cline { 2 - 4 } & $\begin{array}{c}\text { Last Answer } \\
\text { (2 marks) }\end{array}$ & 0.829 & 0.899 & & \\
\hline
\end{tabular}

Table 5 shows the mean for homogeneous DE was 4.024 indicating good score by students out of 6.5 marks. We can see that the mean for integration by $\mathrm{u}$-substitution and final answer were 0.671 and 0.829 respectively that imply poor scores. On the average students scored 5.524 marks for Question 2 indicating that a moderate score was obtained by students in solving homogeneous DE.

Table 6: Performance of students in Question 2

\begin{tabular}{|c|c|c|c|c|c|c|}
\hline \multirow[t]{2}{*}{$\begin{array}{c}\text { Completio } \\
\text { n Level }\end{array}$} & \multicolumn{2}{|c|}{$\begin{array}{c}\text { Apply } \\
\text { y = vx } \\
(6.5 \mathrm{~m})\end{array}$} & \multicolumn{2}{|c|}{$\begin{array}{c}\mathrm{u}- \\
\text { substitution } \\
(\mathbf{1 . 5} \mathrm{m})\end{array}$} & \multicolumn{2}{|c|}{$\begin{array}{c}\text { Last } \\
\text { Answer } \\
(2 \mathrm{~m})\end{array}$} \\
\hline & f & $(\%)$ & $\mathbf{f}$ & $\%$ & f & $(\%)$ \\
\hline $\mathrm{C}$ & 14 & 34.1 & 1 & 2.4 & 29.3 & 12 \\
\hline I & 25 & 61 & 18 & 43.9 & 21.9 & 9 \\
\hline $\mathrm{W}$ & 2 & 4.9 & 22 & 53.7 & 48.8 & 20 \\
\hline Total & 41 & 100 & 41 & 100 & 41 & 100 \\
\hline
\end{tabular}

Table 6 indicates that most of the students $(\mathrm{f}=25,61 \%)$ gave incomplete answers when using the substitution $y=v x$, only two $(\mathrm{f}=2,4.9 \%)$ students were unable to apply the substitution $\mathrm{y}=\mathrm{vx}$ in the homogeneous equation. About half $(\mathrm{f}=22,53.7 \%)$ of the population were unable to apply 
integration by $\mathrm{u}$-substitution and only one ( $\mathrm{f}=1,2.4 \%)$ student could solve it correctly. Thus, only 12 students were able to answer Question 2 correctly and 20 students gave the wrong answer. The remaining students generated incomplete answers.

Description of students' performance in Question 3

Table 7: Description of marks for Bernoulli equation

\begin{tabular}{|c|c|c|c|c|c|}
\hline & Case & $\underset{\mathbf{n}}{\text { Mea }}$ & SD & $\begin{array}{l}\text { Overal } \\
\text { l Mean }\end{array}$ & SD \\
\hline \multirow{3}{*}{ Q3 } & $\begin{array}{c}\text { Apply } \\
\mathrm{v}=\mathrm{y}^{1-\mathrm{n}} \\
\text { (4 marks) }\end{array}$ & 1.488 & 1.595 & \multirow{3}{*}{2.707} & \multirow{3}{*}{3.537} \\
\hline & $\begin{array}{c}\text { Integration } \\
\text { by parts } \\
(4 \text { marks })\end{array}$ & 0.951 & 1.572 & & \\
\hline & $\begin{array}{c}\text { Last } \\
\text { Answer } \\
(2 \text { marks })\end{array}$ & 0.268 & 0.6113 & & \\
\hline
\end{tabular}

Table 7 shows that the mean for applying the substitutions $\mathrm{v}=\mathrm{y}^{1-\mathrm{n}}$ is 1.488 , indicating that students' score for this case is significantly poor. The score for integration by parts was worse with a mean of 0.951 . Due to these scores, the final answer was affected with students scoring a mean of only 0.268. This shows that students' achievement for Question 3 was very poor.

Table 8: Performance of students in Question 3

\begin{tabular}{|c|c|l|c|c|c|c|}
\hline \multirow{2}{*}{$\begin{array}{c}\text { Completio } \\
\text { n Level }\end{array}$} & \multicolumn{2}{|c|}{$\begin{array}{c}\text { Apply } \\
\mathrm{v}=\mathrm{y}^{1-\mathrm{n}} \\
\mathbf{( 4 ~} \mathbf{~ m})\end{array}$} & \multicolumn{2}{|c|}{$\begin{array}{c}\text { Integration } \\
\text { by parts } \\
\mathbf{( 4 ~ m )}\end{array}$} & \multicolumn{2}{c|}{$\begin{array}{c}\text { Last } \\
\text { Answer } \\
(\mathbf{2} \text { m) }\end{array}$} \\
\cline { 2 - 7 } & $\mathbf{f}$ & $\mathbf{( \% )}$ & $\mathbf{f}$ & $\boldsymbol{\%}$ & $\mathbf{f}$ & $\mathbf{( \% )}$ \\
\hline C & 7 & 17.1 & 6 & 14.6 & 2 & 4.9 \\
\hline I & 18 & 43.9 & 8 & 19.5 & 5 & 12.2 \\
\hline W & 16 & 39 & 27 & 65.9 & 34 & 82.9 \\
\hline Total & 41 & 100 & 41 & 100 & 41 & 100 \\
\hline
\end{tabular}

Table 8 reveals that at the first stage in applying the substitution $v=y^{1-n}$, almost half of the students $(\mathrm{f}=18$, $43.9 \%)$ gave incomplete solutions followed by 16 students $(\mathrm{f}=16,39 \%)$ give wrong answers and only 7 students $(\mathrm{f}=7$, $17.1 \%$ ) gave the complete solution. For integration by parts, we found that most of the students $(\mathrm{f}=27,65.9 \%)$ failed to solve integration by parts and only 6 students were able to understand and complete the answer correctly. The remaining students $(\mathrm{f}=8,19.5 \%)$ gave incomplete solutions. Thus, only two students ( $\mathrm{f}=2,4.9 \%$ ) were able to get full marks and the majority of students were unable to find the final answer. Then the remaining students $(\mathrm{f}=5,12.2 \%)$ generated incomplete answers.

\section{Examples of students' solution for each question}

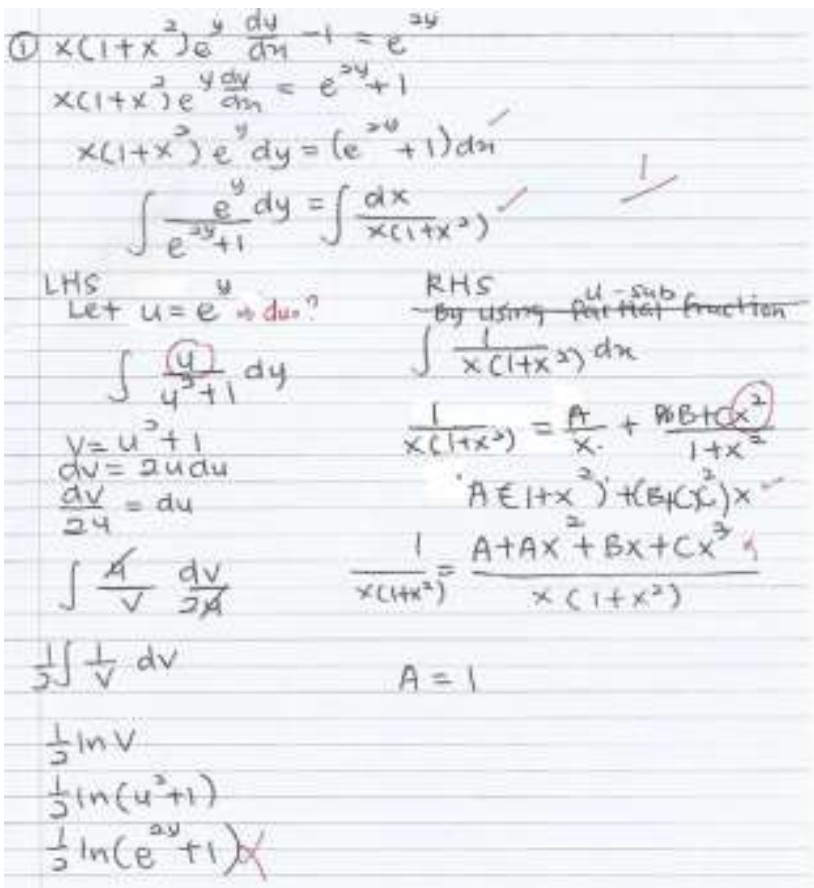

Fig. 3: Errors made by student A

Fig. 3 shows that student A have difficulties choosing the correct u-substitution, especially when it comes to working with exponents. This student also failed to write the correct standard form of partial fractions decomposition.

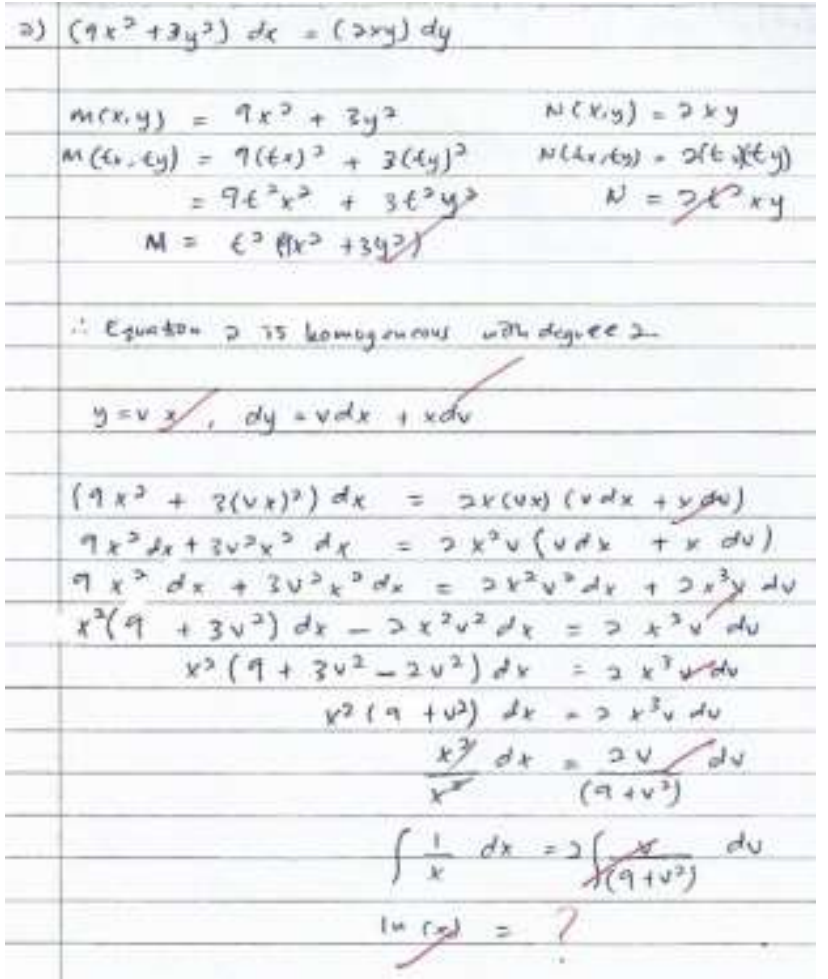

Fig. 4: Errors made by student B

Fig. 4 shows that student $\mathrm{B}$ able to solve the first stage of homogeneous differential equation. However, the working solution had been stuck when she had to integrate using u-substitution method. 


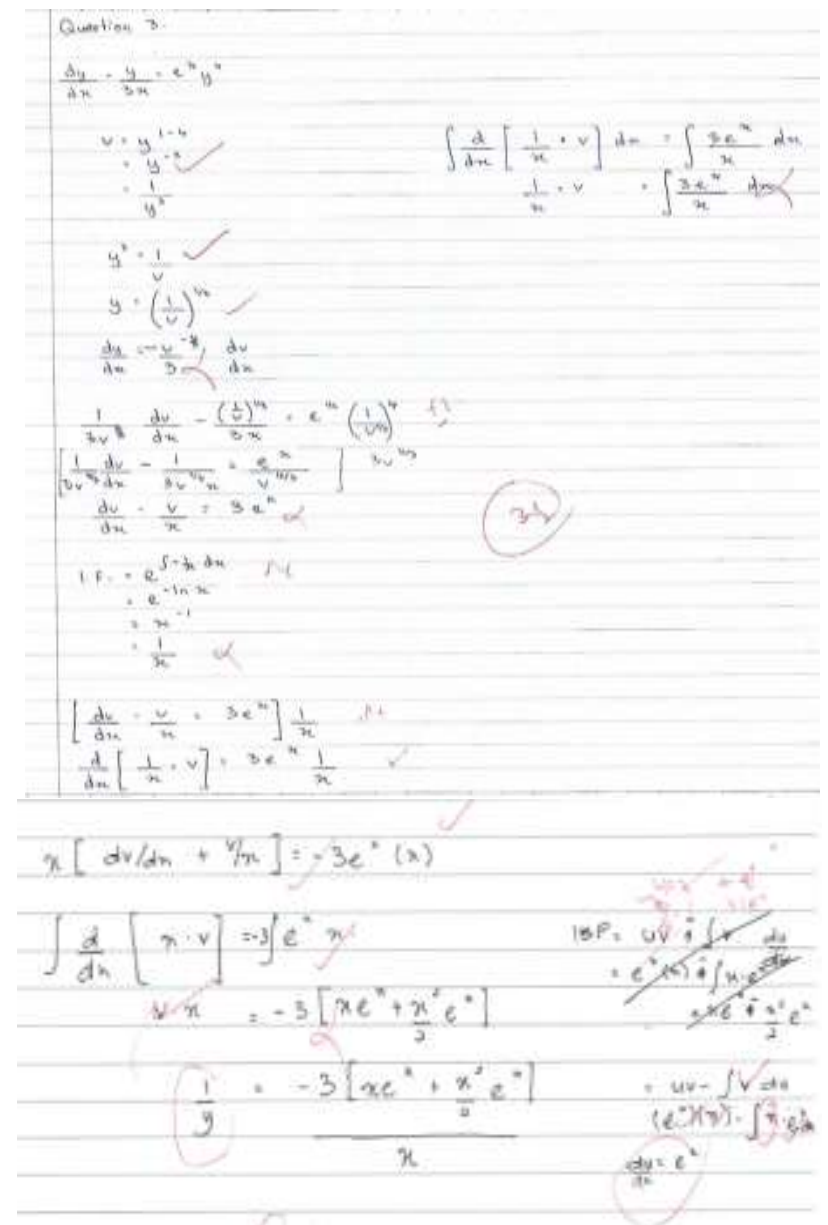

Fig. 5: Errors made by student C and D

Fig. 5 shows that student $\mathrm{C}$ has difficulties reducing the Bernoulli equation to linear DE. Meanwhile, student D managed to get the linear $\mathrm{DE}$, but he failed to complete the solution when he could not solve the integration using integration by parts.

\section{CONCLUSION}

The students' errors in solving first-order differential equations are evidently based on the weak procedural knowledge on integration techniques of the sample of 41 students. This study showed that students were able to separate the variables in the separable differential equation. However, they find difficulties whenever it comes to the step that required the used of $\mathrm{u}$-substitution and partial fractions decomposition.

This study also showed that, most of the students were able to apply the substitution $y=v x$ to the homogeneous DE in order to reduce it to a separable equation. However, again they failed to complete the solutions because of the integration by parts technique needed.

It was also found from the students' solutions in the test that many of them were unable to use the appropriate substitution in order to reduce the Bernoulli equation to linear DE. Therefore, they could not complete the rest of the solution steps. This resulted in the very poor achievement for this question.

The results of the investigation may help to cause the students to admit their struggles in solving first-order DEs and identify the reasons underlying their difficulties. They should spend time reviewing previous lessons on Calculus especially integration techniques. This should be done at the start of the semester.

Instructors also need to play a role in helping students with revision. Additionally, instructors can use online learning tools to ensure that students have a solid foundation in Calculus before embarking on ODE course materials.

\section{ACKNOWLEDGMENT}

The study is financially funded by Faculty of Computer and Mathematical Sciences, Universiti Teknologi MARA, Perak Branch, Tapah Campus. Special thanks are also extended to those participated in this study.

\section{REFERENCES}

1. J. M. Said, E. Arul, S. A. Razak, N. A. Yahya, and N. H. Jamian, "The design and implementation of Massive Open Online Course (MOOC) for Ordinary Differential Equations (ODE)," International Journal of Engineering and Technology, 7(4.33), 2018, pp. 119-122.

2. S. A. Razak, J. M. Said, E. Arul, N. A. Yahya, and N. H. Jamian, "Students perception on learning Ordinary Differential Equations (ODEs) using MOOCs," Multidisciplinary Informatics Journal, 1(2), 2018, pp. 135-143.

3. R. P. Khotimah and M .Masduki, "Improving teaching quality and problem solving ability through contextual teaching and learning in differential equations: A lesson study approach," JRAMathEdu (Journal of Research and Advances in Mathematics Education), 1(1), 2016, pp. $1-13$.

4. A. Selathattin, "Traditional instruction of differential equations and conceptual learning," Teaching Mathematics and Its Application, 29, 2010, pp. $94-107$.

5. A. Bibi, S. N. S. Zamri, N. A. M. Abedalaziz, and M Ahmad, "Teaching and learning of differential equation: A critical review to explore potential area for reform movement," International Journal for Innovative Research in Multidisciplinary Field, 3(6), 2017, pp. 225-235.

6. H. Kashefi, Z. Ismail, Y. M. Yusof, and R. A. Rahman, "Fostering mathematical thinking in the learning of multivariable calculus through computer-based tools," Procedia, Social and Behavioral Sciences, 8, 2012, pp. 5534-5540.

7. F. P. Ferrer, "Investigating students' learning difficulties in integral calculus," PEOPLE: International Journal of Social Science, 2, 2016, pp. 54-68.

8. T. S. Peterson, Calculus with Analytic Geometry. New York: Harper, 1960.

9. J. Stewart, Calculus. Boston: Cengage Learning, 2015.

10. F. Nursyahidah and I. U. Albab, "Investigating student difficulties on integral calculus based on critical thinking aspects," Jurnal Riset Pendidikan Matematika, 4(2), 2017, pp. 211-218.

11. N. Mahir, "Conceptual and procedural performance of undergraduate students in integration," International Journal of Mathematical Education in Science and Technology, 40 (2), 2009, pp. 201-211.

12. F. A. Razak, N. Baharun, N. A. Deraman, and N. R. P. Ismail, "Assessing students' abilities in interpreting the correlation and regression analysis," Journal of Fundamental and Applied Sciences, 9(5S), 2017, pp. 644-661. 